\title{
IMPLEMENTASI PROJECT BASED LEARNING (PBL) DAN PENILAIAN AUTENTIK DALAM PEMBELAJARAN DRAMA INDONESIA
}

\author{
Fathullah Wajdi \\ Program Studi Pendidikan Bahasa Indonesia \\ Sekolah Pascasarjana, Universitas Pendidikan Indonesia \\ E-mail: fathullahwajdi@yahoo.com \\ DOI: http://dx.doi.org/10.17509/bs_jpbsp.v17i1.6960
}

\begin{abstract}
Abstrak
Penelitian ini bertujuan menjelaskan implementasi dan hasil implementasi model pembelajaran project based learning (PBL) dan penilaian autentik agar dapat dijadikan contoh dan pedoman guru dalam melaksanakan pembelajaran drama dan sastra pada umumnya. Metode penelitian yang digunakan adalah metode kualitatif dengan tahapan menentukan asumsi, menentukan desain, menentukan aturan penelitian, mengumpulkan data, melakukan perekaman data, menganalisis data, melakukan verivikasi tahap penelitian, dan menarasikan atau mendeskripsikan hasil penelitian. Penelitian ini menghasilkan beberapa temuan yaitu (1) project based learning (PBL) dan penilaian autentik sangat sesuai diterapkan dalam pembelajaran drama; (2) model pembelajaran dan penilaian ini mudah dilaksanakan dalam pembelajaran drama; (3) model pembelajaran dan penilaian ini dilaksanakan dengan mengikuti langkah-langkah pembelajaran yang sederhana namun menantang siswa untuk berpartisipasi aktif; dan (4) model pembelajaran dan penilaian ini menghasilkan kompetensi siswa yang memuaskan, yaitu dengan nilai rata-rata 3,55 dan 3,63 pada skala 1-4 dengan kualifikasi sangat baik. Kompetensidiukur melalui penilaian autentik dengan rubrik penilaian parameter pertunjukan drama. Berdasarkan pembehasan tersebut dapat disimpulkan bahwa (1) model pembelajaran project based learning (PBL) dan penilaian autentik dapat dilaksanakan dengan baik dan mudah; dan (2) hasil implementasi model berupa nilai pembelajaran drama menunjukkan hasil yang sangat memuaskan.
\end{abstract}

Kata kunci: PBL, penilaian autentik, drama Indonesia

\section{IMPLEMENTATION OF PROJECT BASED LEARNING (PBL) AND AUTHENTICAL ASSESSMENT IN LEARNING INDONESIAN DRAMA}

\begin{abstract}
This study aims to explain the implementation of project learning model (PBL) and authentic assessment that can serve as a model for teachers in teaching drama and literature in general. This is a qualitative research study with the following stages: determine assumptions, determine the design, determine the rules of research, collect data, perform data recording, analyze data, verify the research stage, and describe the research results. This research generates several findings: (1) project based learning (PBL) and authentic assessment fit well with the teaching of drama; (2) the model in question is easy to implement in teaching drama; (3) the learning steps involved are simple yet stimulate the students to actively participate; and (4) this model leads to satisfactory student competence, with an average of 3.55 and 3.63 on a 1-4 scale with excellent qualifications. Competitiveness is measured through the authentic judgment with the rubric of the drama performance parameter. Based on the discussion, it can be concluded that (1) project based learning (PBL) and authentic assessment can be implemented well and easily; and (2) the result of model implementation in teaching drama indicates very satisfactory results.
\end{abstract}

Keywords: project based learning, authentic assessment, Indonesian drama 


\section{PENDAHULUAN}

Pembelajaran drama dalam mata pelajaran bahasa Indonesia merupakan salah satu kegiatan yang tidak hanya melatih memahami karakter tokoh dan memerankannya sesuai pesanan naskah seperti dijelaskan Syukron, Subyantoro, dan Yuniawan (2016, p. 49) bahwa drama adalah karya sastra yang bertujuan menggambarkan kehidupan dengan menyampaikan pertikaian dan emosi dengan gerak dan dialog yang dipentaskan, pembelajaran ini juga melatih keterampilan berbahasa siswa. Keterampilan yang paling dominan dalam pembelajaran ini yaitu keterampilan berbicara sesuai dengan unsur dominan drama yaitu dialog. Irawan, Sudiana, dan Wendra (2014, p.2) menjelaskan bahwa keterampilan berbicara harus dikembangkan melalui suatu latihan. Salah satu latihan pengembangan ketermpilan berbicara itu adalah bermain drama.Dalam bermain drama, terdapat suatu kegiatan memerankan tokoh yang ada dalam naskah drama. Pemeranan tokoh dalam drama tersebut dilakukan dengan alat utama, yakni berupa percakapan (dialog).

Setiaji (2014, p.115) menjelaskan bahwa pembelajaran drama mempunyai peran yang penting untuk melatih peserta didik mengasah kemampuan berekspresi dalam seni peran. Pembelajaran drama juga berfungsi untuk melatih kepekaan karakter peserta didik dalam menghadapi setiap permasalahan yang ada.Kegiatan memerankan tokoh dalam bermain drama dapat mengasah mental peserta didik.

Begitu banyak dan luas manfaat pembelajaran drama yang sejatinya menjadi kompetensi siswa sebagaimana sebagian telah diuraikan di atas.Pebelajaran ini mampu memberikan sumbangan kompetensi yang sangat bermanfaat bagi perkembangan dan masa depan siswa. Menimbang manfaat kompetensi tersebut, pembelajaran drama tidak dapat dipandang sebelah mata. Dengan demikian, pembelajaran drama sudah seharusnya mendapatkan perhatian yang sama bahkan lebih daripada pembelajaran lain terutama dalam proses pembelajarannya. Faktanya, pembelajaran drama di sekolah atau perguruan tinggi masih jauh panggang dari api. Marantika (2014, p.93) menjelaskan bahwa drama merupakan salah satu genre sastra yang juga diajarkan baik pada sekolah lanjutan maupun perguruan tinggi. Pengajaran drama di sekolah dan perguruan tinggi di Indonesia, selama ini disinyalir masih kurang memuaskan.Berbagai persoalan yang mempengaruhi kondisi tersebut masih berkaitan dengan masalah lemahnya strategi pembelajaran.

Masih pada halaman yang sama Marantika menjelaskan factor penyebab gagalnya pembelajaran drama yaitu banyak pengajar yang masih belum memahami secara baik, bagaimana mengajarkan drama. Drama hanya dimaknai sebagai sandiwara yang akan sulit diajarkan di kelas karena berbagai kendala. Setiaji (2014, p. 116) menambahkan persoalan pembelajaran drama yang lain yaitu pemberian materi yang berkaitan dengan kemampuan memerankan tokoh drama masih kurang. Peserta didik harus mencari dan mempraktikkan sndiri teknik-teknik bermain drama.Contoh teknik bermain peran yang ditunjukkan oleh guru masih kurang maksimal.Model pembelajaran yang digunakan juga msih sangat terbatas.

Permasalahan pembelajaran drama sebenarnya tidak jauh berbeda dengan permasalahan pembelajaran sastra pada umumnya. Permasalahan pembelajaran sastra antara lain diungkapkan Suryatin (1999, p. 52-53) yang menjelaskan bahwa terdapat tiga penyebab permasalahan pembelajaran sastra, yaitu guru, siswa dan sarana belajar. Berkaitan dengan guru, Suryatin menjelaskan empat faktor yang menjadi penyebabnya, yaitu (1) rendahnya minat baca guru terhadap karya sastra; (2) kurangnya pengalaman guru dalam mempelajari teori sastra, (3) kurangnya pengalaman guru mengapresiasi karya sastra, dan (4) keluasan cakupan kurikulum yang membuat guru kewalahan dalam mengatur 
waktu dengan plot waktu yang terbatas.

Pendapat serupa juga dikemukakan Hamid (2007, p. 12-14) bahwa pengajaran sastra di lembaga pendidikan formal dari hari ke hari semakin sarat dengan berbagai persoalan di antaranya: 1) pengetahuan kemampuan dasar dalam bidang kesustraan para guru sangat terbatas, 2) materi kesastraan yang mereka peroleh selama mengikuti pendidikan formal di LPTK yang sangat terbatas, 3) materi kesastraan yang mereka peroleh selama mengikuti pendidikan formal di perguruan tinggi (PT) sangat terbatas, 4) Materi kuliah kesastraan yang mereka peroleh lebih bersifat teoritis, sedangkan yang mereka butuhkan di lapangan lebih bersifat praktis.

Amarzaki (2005) dengan sudut pandang yang sedikit berbeda menjelaskan bahwa pembelajaran sastra belum mampu membuka mata siswa terhadap daya tarik sastra. Kalau sekedar menghafal nama pengarang, judul karya, dan periodisasi sastra saja memang belum cukup menarik bagi siswa. Sekedar menentukan unsur-unsur intrinsik dan ekstrinsik karya sastra, tanpa mengaitkannya dengan pengalaman siswa juga belum mampu membuka mata siswa.
Sekedar membaca puisi atau menentukan rima juga belum mampu memunculkan kreativitas pada siswa.

Persoalan lain berkaitan dengan pembelajaran drama adalah persoalan penilaian. Dalam melakukan penilaian perkembangan pemahaman dan keterampilan siswa dalam pembelajaran drama sebagian besar guru masih menggunakan jenis penilaian yang sama dengan pembelajaran lain, yaitu penilaian yang dilakukan pada hasil akhir pembelajaran.

Berkaitan dengan penilaian, Sutrisna, Nengah, dan Arifin (2013) mengutip pendapat Sarwiji (2005) yang menemukan bahwa kemampuan guru dalam menyiapkan dan melakukan penilaian masih kurang dan bahkan masih banyak guru yang belum memiliki pemahaman yang memadai tentang sistem penilaian yang sesuai dengan penerapan kurikulum yang berlaku.

Dalam hasil penelitiannya Wajdi (2017) menguraikan hasil penilaian akhir yang dilakukan guru dalam pembelajaran drama dengan metode konvensional sebagai berikut.

Tabel 1. Hasil penilaian akhir pembelajaran drama dengan metode konvensional

\begin{tabular}{llcc}
\hline No. & Item Penilaian & $\begin{array}{c}\text { Rata- } \\
\text { Rata } \\
\text { Nilai }\end{array}$ & Kesimpulan \\
\hline a. & Pengucapan/Pelafalan & & \\
\hline 1 & Ucapan terdengar jelas oleh penonton & 3.53 & $\begin{array}{c}\text { SANGAT } \\
\text { BAIK }\end{array}$ \\
\hline 2 & Ucapan sesuai dengan karakter tokoh & 1.66 & CUKUP \\
\hline b. & Intonasi & & \\
\hline 1 & Variasi Intonasi & 1.53 & CUKUP \\
\hline 2 & Intonasi sesuai dengan karakter & 1.47 & KURANG \\
\hline c. & Pengaturan Nada dan Jeda & & \\
\hline 1 & Pengaturan Nada Tepat & 1.66 & CUKUP \\
\hline 2 & Pengaturan Jeda Tepat & 1.45 & KURANG \\
\hline 3 & Pengaturan Tekanan Tepat & 1.32 & KURANG \\
\hline d. & Intensitas dan Kelancaran Berbicara & & \\
\hline 1 & Kelancaran Berbicara Konsisten & 1.55 & CUKUP \\
\hline e. & Kemunculan Pertama & & \\
\hline & & &
\end{tabular}


84 Jurnal Pendidikan Bahasa dan Sastra, Volume 17, Nomor 1, April 2017, blm. 81-97

\begin{tabular}{clcc}
1 & Kemunculan Yertama Member Kesan Karakter & 1.45 & KURANG \\
\hline f. & Blocking & & \\
\hline 1 & Pemanfaatan ruang yang ada & 1.39 & KURANG \\
\hline g. & Ekspresi & 1.58 & CUKUP \\
\hline 1 & Ekspresi Dialog Menggambarkan Karakter & 1.47 & KURANG \\
\hline 2 & Ekspresi Tokoh Menggambarkan Karakter & & \\
\hline h. & Pandangan Mata dan Gerakan Tubuh & 1.26 & KURANG \\
\hline 1 & Pandangan Mata sesuai dengan Karakter & 1.61 & CUKUP \\
\hline 2 & Gerakan Tubuh Bersifat Alamiah & 1.29 & KURANG \\
\hline 3 & Movement sesuai dengan Karakter & 1.42 & KURANG \\
\hline 4 & Gestur sesuai dengan Karakter & 1.60 & C \\
\hline & Jumlah Rata-Rata & &
\end{tabular}

Berdasarkan hasil penilaian tersebut hanya satu item penilaian yang menghasilkan nilai dengan kategori sangat baik yaitu pelafalan. Hal ini menunjukkan bahwa kemampuan siswa dalam mengaktualisasikan diri sangat baik tetapi kemampuan ini bersifat serampangan dan tidak terarah. Siswa hanya berusaha menyelesaikan teks drama yang sudah mereka hafalkan tanpa dibarengi dialog yang bersifat alami menunjukkan karakter tokoh yang mereka perankan. Siswa tidak memahami bahwa dalam memerankan tokoh dalam sebuah drama dituntut totalitas yang menggambarkan kehidupan manusia.

Sementara itu, pada bagian lain kelancaran berbicara tersendat-sendat dan terkesan kurang persiapan. Variasi intonasi yang menunjukkan karakter tokoh juga diabaikan. Intonasi yang digunakan adalah intonasi asli siswa dengan aksen kedaerahan. Di tengah-tengah adegan siswa sering keluar dari konteks pementasan drama. Reaksi penonton sangat mempengaruhi mereka sehingga membuat pandangan mata yang tidak jelas, gerakan tubuh yang tidak mendukung pemeranan, dan melakukan kegiatan lain yang tidak mendukung pementasan pada saat tidak mendapat giliran berdialog. Tidak jarang siswa tertawa untuk menutupi kekurangannya sat pementasan. Ini menunjukkan blocking dan ekspresi yang tidak jelas.

Hal ini terjadi disebabkan oleh pembelajaran yang dilakukan seadanya.
Dengan alasan keterbatasan waktu dan tuntutan kurikulum pembelajaran drama dilaksanakan dengan metode ceramah, pemberian tugas dan diakhiri dengan penilaian pertunjukan yang dilakukan tanpa persiapan yang matang.

Menyoroti masalah kreativitas siswa, pembelajaran drama membutuhkan guru yang kreatif yang mampu memberikan peluang siswa untuk mengembangkan kreativitas mereka. Selain pemahaman materi drama yang matang, guru juga membutuhkan model pembelajaran yang memudahkan guru menjalankan tugasnya, model pembelajaran dengan langkah-langkah sederhana dan jelas. Kreativitas siswa harus mendapat penghargaan yang baik, valid, dan berkeadilan dengan penilaian yang tidak hanya mengandalkan peilaian akhir tetapi juga penilaian proses. Dengan demikian, pembelajaran drama membutuhkan model yang tepat dengan penilaian yang tepat pula. Model pembelajaran yang sesuai dengan karakteristika pembelajaran drama yang kreatif adalah model project based learning (PBL) dan jenis penilaian yang tepat adalah penilaian autentik.

Permasalahan yang dibahas dalam penelitian ini adalah (1) bagaimana implementasi model pembelajaran project based learning (PBL) dan penilaian autentik dalam pembelajaran drama Indonesia? (2) bagaimana hasil implementasi model pembelajaran project based learning (PBL) dan 
penilaian autentik dalam pembelajaran drama Indonesia?

Project-based learning merupakan sebuah model pembelajaran yang sudah banyak dikembangkan di negara-negara maju seperti Amerika Serikat. Jika diterjemahkan dalam bahasa Indonesia, Project Based Learning (PBL) bermakna sebagai pembelajaran berbasis proyek (Rais, 2010, p.4). Pembeajaran berbasis proyek adalah suatu pendekatan pendidikan yang efektftif yang berfokus pada jreatifitas berpikir, pemecahan masalah, dan interakksi antara siswa dengan kawan sebaya mereka untuk menciptakan dan menggunakan pengetahuan baru.Khususnya ini dilakukan Dalam konteks pembelajaran ktif, dialog ilmiah dengan supervisor yang aktif sebagai peneliti (Asan, 2005 dalam Jagantara, Adnyana, dan Widiyanti, 2014).

Project-based learning (PBL) seperti ditulis Jonassen (1997) dalam Jagantara, Adnyana, dan Widiyanti (2014) merupakan pendekatan konstruktif yang memberikan instruksi dengan fokus pada dunia nyata yang kurang terstruktur. Pusat orientasi PBL lebih meyarankan kesempatan belajar berbasis inquiri yaitu pengalaman terstruktur didasarkan pada keyakinan bahwa pembelajaran terjadi ketika individu diminta untuk melakukan penyelidikan dan seputar masalah yang terjadi. Brears, Mac Intyre, dan O'Sullivan (2011) menjelaskan bahwa proses penyelidikan mungkin dimulai dengan refleksi diri dan evaluasi. Oleh karena itu, Brears dkk. mencatat pentingnya tiga aspek penyelidikan (pencarian terhadap pemecahan masalah), yaitu (1) kerja kelompok kolaboratif, (2) penekanan pada analisis dan evaluasi,dan (3) menambahkan refleksi (praktik). Untuk mendorong diberlakukannya pedagogis ketiga aspek dari proses PBL, kami menawarkan tiga unsur yang mendukung yaitu penyelidikan,berpikir kritis,dan pengambilan keputusan (Pryor dan Kang dalam Capraro, Capraro dan Morgan (Eds), 2013, p.29).

Dengan sudut pandang yang sedikit berbeda Baron (1998, p.271) seperti dikutip Lindawati, Fatmariyanti, dan Maftukhin, 2013, p.43) berpendapat bahwa project based learning adalah suatu pendekatan pembelajaran yang membenturkan siswa kepada masalahmasalah praktis melalui stimulus dalam belajar. Peranan guru sangat penting dalam memberikan stimulus-stimulus agar siswa dapat melakukan pembelajaran secara mandiri, menemukan pemahamannya sendiri dan mengembangkan kreatifitasnya secara kolaboratif.

Roessingh dan Chambers (2011, p.60) mengemukakan bahwa elemen penting dalam desain proyek yaitu, (1) gambaran proyek dengan rasionalisasinya, (2) seperangkat tujuan pembelajaran yang jelas dan konsepkonsep kunci, (3) daftar bahan dan sumber daya, (4) memungkinkan seperangkat tugas, dan (5) kriteria penilaian dan rubrik.

Berbeda dengan model-model tradisional yang mementingkan kecepatan pencapaian target kurikulum yang menghasilkan pembelajaran yang singkat dan pada tataran kulit, project based learning (PBL) memberikan pengalaman belajar yang detail, rinci, menantang, dan dalam jangka waktu yang lebih panjang dengan target terselesaikannya proyek yang menghasilkan sebuah produk, karya siswa yang memuaskan. Menurut Buck Institute for Education (Samanthis \& Sulistyo, 2014:25), terdapat perbedaan antara pembelajaran tradisional dan project based learning. Berikut ini perbedaan tersebut. 
86 Jurnal Pendidikan Bahasa dan Sastra, Volume 17, Nomor 1, April 2017, blm. 81-97

Tabel 2. Perbandingan Pembelajaran Tradisional dengan Project Based Learning (PBL)

\begin{tabular}{|c|c|c|}
\hline Aspek Pendidikan & $\begin{array}{c}\text { Penekanan Pembelajaran } \\
\text { Tradisional } \\
\end{array}$ & $\begin{array}{c}\text { Penekanan Project Based } \\
\text { Learning }\end{array}$ \\
\hline Fokus Kurikulum & $\begin{array}{l}\text { Cakaupan isi pengetahuan tentang fakta } \\
\text { belajar keterampilan building block dalam } \\
\text { isolasi. Mengikuti urutan kurikulum } \\
\text { secara ketat. }\end{array}$ & $\begin{array}{l}\text { Kedalaman pemahaman penguasaan } \\
\text { konsep dan prinsip pengembangan } \\
\text { keterampilan permbacaan masalah } \\
\text { kompleks. Mengikuti minat siswa. }\end{array}$ \\
\hline Lingkup dan Urutan & $\begin{array}{l}\text { Berjalan dari blok ke blok atau unit ke } \\
\text { unit. }\end{array}$ & $\begin{array}{l}\text { Unit-unit besar terbentuk dari } \\
\text { problem dan isu vang kompleks. }\end{array}$ \\
\hline Peranan Guru & $\begin{array}{lll}\begin{array}{l}\text { Memusat, focus } \\
\text { penceramah, } \\
\text { pembelajaran. }\end{array} & \text { dan } & \begin{array}{l}\text { disiplin, } \\
\text { direktur }\end{array} \\
\end{array}$ & $\begin{array}{l}\text { Meluas, focus, interdidipliner, } \\
\text { penyedia sumber belajar dan } \\
\text { partisipan di dalam kegiatan belajar. }\end{array}$ \\
\hline Fokus Pengukuran & $\begin{array}{l}\text { Ahli produk skor tes, membandingkan } \\
\text { dengan yang lain, reproduksi informasi } \\
\text { teks, ceramah dan presentasi. }\end{array}$ & $\begin{array}{l}\text { Unjuk kerja standar dan kemajuan } \\
\text { dari waktu ke waktu, demonstrasi } \\
\text { pemahaman langsung dari sumber } \\
\text { asli, bahan-bahan tercetak, interview, } \\
\text { dokumentasi, dan lain-lain }\end{array}$ \\
\hline $\begin{array}{l}\text { Bahan-Bahan } \\
\text { Pembelajaran }\end{array}$ & $\begin{array}{l}\text { Kegiatan dan lembar latihan } \\
\text { dikembangkan guru. }\end{array}$ & $\begin{array}{l}\text { Data dan bahan dikembangkan oleh } \\
\text { siswa. }\end{array}$ \\
\hline $\begin{array}{l}\text { Penggunaan } \\
\text { Teknologi }\end{array}$ & $\begin{array}{l}\text { Pendukung feriferal dijalankan guru } \\
\text { yang berguna untuk perluasan } \\
\text { presentasiguru. }\end{array}$ & $\begin{array}{l}\text { Utama, integral, diarahkan guru } \\
\text { kegunaannya untuk memperluas } \\
\text { presentasi siswa atau penguatan } \\
\text { kemampuan siswa. }\end{array}$ \\
\hline Konteks Kelas & $\begin{array}{l}\text { Siswa bekerja sendiri, siswa } \\
\text { berkomptisi satu dengan lainnya, dan } \\
\text { siswa menerima informasi dari guru. }\end{array}$ & $\begin{array}{l}\text { Siswa bekerja dalam kelompok, siswa } \\
\text { berkolaboratif satu dengan yang } \\
\text { lainnya. Siswa mengkonstruksi, } \\
\text { berkontribusi, dan melakukan sintesis } \\
\text { informasi. }\end{array}$ \\
\hline Peranan Siswa & $\begin{array}{l}\text { Menjalankan perintah guru. Pengingat } \\
\text { dan pengulang fakta. Pembelajar } \\
\text { menerima dan menyelesaikan tugas- } \\
\text { tugas laporan pendek. Pengetahuan } \\
\text { tentang fakta istilah dan isi. }\end{array}$ & $\begin{array}{l}\text { Melakukan kegiatan belajat yang } \\
\text { dirahkan oleh diri sendiri, pengkai, } \\
\text { integratr, dan penyaji ide. Siswa } \\
\text { menentukan tugas mereka sendiri } \\
\text { dan bekerja secara independen dalam } \\
\text { waktu yang besar. Pemahaman dan } \\
\text { aplikasi ide dan proses yang } \\
\text { kompleks dalam pengetahuan. }\end{array}$ \\
\hline $\begin{array}{l}\text { Tujuan } \\
\text { Pendek }\end{array}$ & $\begin{array}{l}\text { Pengetahuan luas. Lulusan yang } \\
\text { memiliki pengetahuan yang berhasil } \\
\text { pada tes standar pencapaian. }\end{array}$ & $\begin{array}{l}\text { Lulusan yang berkarakter dan } \\
\text { terampil mengembangkan diri, } \\
\text { mandiri, dan belajar sepanjang hayat. }\end{array}$ \\
\hline
\end{tabular}

Sementara itu pada bagian lain The George Lucas Educational Foundation (2003) menjelaskan langkah-langkah pembelajaran dengan menggunakan model pembelajaran project based learning (PBL) sebagai berikut:

1. Question

Start with the Essential Question. Take a real-world topic and begin an in-depth investigation. Make sure it is relevant to your students.

2. Plan

Plan which content outcomes will be addressed while answering the question. Involve students in the questioning, planning, and project- building process. Teacher and students brainstorm activities that support the inquiry.

3. Schedule

Teacher and students design a timeline for project components. Set benchmarks.

Keep it simple and age-appropriate.

\section{Monitor}

Make the assessment authentic. Know authentic assessment will require more time and effort from the teacher. Vary the type of assessment used.

Assess

5. Facilitate the process. Mentor the process.

Utilize rubrics. 


\section{Evaluate}

Take time to reflect individually and as a group. Share feelings and experiences. Discuss what worked well. Discuss what needs change. Share ideas that will lead to new inquiries, thus new projects.

\section{Pertanyaan pada Awal Pembelajaran}

Kegiatan pembelajaran dimulai dengan memberikan pertanyaan menantang kepada siswa. Pertanyaan yang akan menggiring siswa pada konteks pembelajaran berbasis proyek dan memberikan tugas kepada siswa untuk melakukan sebuah aktifitas yang terkontrol. Pertanyaan yang disampaikan adalah pertanyaan yang berkaitan dengan dunia nyata dan dimulai dengan penyelidikan mendalam.

Dalam pembelajaran drama, drama didekatkan terlebih dahulu dengan faktafakta sosial dalam kehidupan. Drama sebagai sebuah karya sastra dapat dinyatakan sebagai cermin kehidupan nyata.Oleh karena itu, proyek drama (dialog) dapat dilakukan dengan model ini.

\section{Perencanaan Proyek}

Langkah kedua yaitu, siswa, dengan bimbingan guru, menyusun perencanaan proyek yang akan dikerjakan. Penetapan kegiatan-kegiatan yang akan dilakukan dalam proyek dari tahap awal hingga akhir proyek. Kegiatan yang dilakukan dalam perencanaan di antaranya: (1) menentukan ukuran proyek; (2) menentukan aturan main; (3) pemilihan aktifitas-aktifitas yang akan dilakukan sebagai jawaban atas pertanyaan-pertanyaan esensial; (4) menentukan pelaksana-pelaksana proyek dengan tugas dan tanggung jawabnya masingmasing; dan (5) menentukan bahan dan alat yang diperlukan.

\section{Penjadwalan Tahap Kegiatan Proyek}

Pada bagian ini siswa dengan bimbingan guru diminta membuat sebuah jadwal kegiatan yang akan dilakukan berdasarkan perencanaan aktifitas-aktifitas yang akan dilakukan. Tujuan kegiatan ini adalah memberikan pemahaman kepada siswa bahwa untuk melakukan sebuah proyek yang besar, sebuah kelompok kerja membutuhkan jadwal kerja yang baik agar proyek dapat dilaksanakan sesuai rencana. Meskipun demikian, kegiatan ini diupayakan dilakukan dengan sederhana dan tidak membingungkan siswa, mislnya dengan memberikan contoh jadwal kegiatan yang pernah ada.

Setelah mendapatkan pengarahan dari guru, siswa dapat melakukan kegiatan ini di luar jam pembelajaran biasa.Hal ini dilakukan agar siswa tidak diburu waktu yang singkat dan dapat memunculkan kreatifitas mereka.Siswa dapat melakukan eksplorasi dan memperoleh sumber inspirasi yang lebih luas.Siswa mempresentasikan hasil penyusunan jadwal mereka pada kegiatan pembelajaran di sekolah sebagai bentuk tanggung jawab.

\section{Pengawasan Proyek Berjalan}

Dalam melaksanakan proyeknya, siswa mendapat pengawasan dari guru. Pengawasan ini berfungsi bukan hanya sebagai sebuah kontrol kerja namun juga sebenarnya merupakan sebuah proses pembimbingan. Monitoring dilakukan dengan memberikan fasilitas penuh kepada siswa untuk melakukan aktifitasnya dengan sempurna.

\section{Penilaian}

Penilaian dilakukan terhadap hasil kerja siswa dalam proyeknya. Penilaian dilakukan untuk mengukur ketercapaian kompetensi siswa.Oleh karena itu, guru dituntut membuat penilaian seautentik mungkin.

\section{Evaluasi Proyek}

Kegiatan pembelajaran diakhiri dengan kegiatan evaluasi proyek. Kegiatan yang dilakukan adalah guru dan siswa melakukan refleksi pelaksanaan proyek. 
Siswa diminta mengungkapkan apa saja yang telah mereka pahami dan lakukan selama proyek berlangsung. Selain itu, siswa juga diminta mengungkapkan perasaannya dan pengalaman baru yang mereka peroleh.

Membandingkan kedua pendapat ahli tersebut, penelitian inimenggunakan tahapan pembelajaran PBL yang dikemukakan oleh The George Lucas Educational Foundation dengan beberapa pertimbangan berikut:

a. Keakuratan; tahap-tahap pembelajaran memiliki ketepatan sistematis dan lengkap;

b. Kejelasan; tahap-tahap pembelajaran mudah dipahami sehingga lebih mudah diimplementasikan;

c. Kesederhanaan; hal ini tidak dapat dilepaskan dari faktor kejelasan. Kesederhanaan bahasa petunjuk dalam tahap-tahap pembelajaran memudahkan pemahaman dan implementasinya.

d. Kesesuaian dengan pokok bahasan pembelajaran yang akan menjadi objek penelitian.

Weyers (2012) menjelaskan empat strategi dalam mengimplementasikan PBL dengan baik di sekolah. Strategi itu adalah (1) lakukan dengan dua cara; (2) kenali upaya sebelumnya; (3) memanfaatkan kata "dan", (3) menjadikan kelas sebagai tempat terbuka. Vega (2012) menambahkan bahwa untuk menghindari kegagalan dalam implementasi PBL diperlukan pemecahan masalah. Guru dapat menghindari kesalahan umum dengan mengikuti tujuh prosedur yang diadaptasi dari Hung (2008) sebagai berikut:

a. Menentukan konten (konten yang diharapkan siswa).

b. Mengidentifikasi konten tersebut (daftar kegiatan kehidupan nyata di mana peserta didik dapat menerapkan konten yang diinginkan).

c. Mendaftar kemungkinan masalah (membuat daftar masalah yang mungkin terjadi dalam proyek).

d. Menjelaskan potensi solusi (menggambarkan solusi yang paling layak untuk memecahkan masalah dalam proyek serta kemungkinan besar solusi alternatifnya). e. Mengkalibrasiproyek (menggunakan solusi untuk memastikan bahwa pengetahuan dan keterampilan yang dihasilkan oleh solusi yang paling layak sesuai dengan pengetahuan dan keterampilan pada langkah pertama.

f. Menjelaskan tugas (membuat deskripsi tugas, menghapus informasi solusi masalah yang paling layak).

g. Merefleksikan pembelajaran (memberi kesempatan kepada siswa untuk memeriksa kemajuan belajar mereka sendiri agar mereka tahu dan mampu membuat jurnal laporan.

Bagian akhir dari implementasi PBL adalah melakukan evaluasi dan pengetesan terhadap kompetensi siswa. Berkaitan dengan hal ini, Miller (2012) memberikan beberapa saran penerapan standar tes dalam PBL, yaitu (1) jangan menunggu, maksudnya guru tidak perlu menunggu hingga akhir proyek untuk melakukan tes atau penilaian. Tes dapat dilakukan selama proses belajar berlangsung; (2) Kekuatan standar/target pembelajaran, maksudnya ketika guru merancang proyek PBL, pastikan standar tes sesuai dengan target pembelajaran; (3) Implementasi PBL yang sempurna, maksudnya pengetesan atau evaluasi dapat dilakukan pada implementasi PBL yang sempurna. Proyek yang dilaksanakan tanpa kendali akan sulit untuk diterapkan standar tes yang baik dan evaluasi menyeluruh.

Berkenaan dengan penilaian, sebuah proyek yang membutuhkan pemantauan atau monitoringyang ketat membutuhakan penilaian autentik yang mengedepankan penilaian proses namun tidak pula mengabaikan penilaian akhir. Penilaian autentik sebenarnya sudah lama diperkenalkan dalam dunia pendidikan di Indonesia walaupun di beberapa daerah masih terkesan baru dan awam.Penilaian ini baru naik ke permukaan dan ramai-ramai dibicarakan setelah KTSP menyarankan penggunaan pembelajaran kontekstual, dan di pihak lain, penggunaan strategi pembelajaran ini menunjukkan penggunaan penilaian autentik dalam hal 
pengukuran hasil pembelajaran peserta didik. Keadaan itu mirip dengan portofolio yang juga baru menjadi popular setelah adanya sertifikasi guru dan dosen yang mensyaratkan mereka untuk membuat portofolio. Perlu diketahui bahwa penilaian dengan cara portofolio sebenarnya salah satu dari bentuk penilaian autentik (Nurgiyantoro, 2011, p.2223).

Penilaian autentik sering diidentikkan dengan penilaian yang dilakukan berdasarkan keadaan nyata, langsung, berorientasi pada pembelajaran aktif, dan pengukuran yang tidak selalu tetap namun memiliki standar yang jelas.Penilaian autentik memang termasuk dalam jenis penilaian yang tidak mudah dilaksanakan terutama dalam pengadministrasian bila dibandingkan dengan penilaian tradisional. Hal ini didukung pula dengan faktor kebiasaan guru yang telah lama menggunakan penilaian tradisional sebagai satu-satunya cara menilai kompetensi siswa. Bila penilaian dimaksudkan untuk menyelesaikan masalah pengadministrasian, maka penilaian tradisionallah jawabannya, dengan catatan, bila perlu pengadministrasian tidak dilakukan.Namun, penilaian dilakukan bukan dengan tujuan administratif belaka.Penilaian dilakukan dalam rangka mengumpulkan data-data sebagai bahan dalam menentukan sebuah keputusan tentang keberhasilan sebuah pembelajaran.

Sebagai penilaian kinerja atau penilaian berbasis kinerja, disebut demikian karena siswa diminta melakukan tugastugas bermakna.Beberapa ahli pendidikan membedakan penilaian autentik dengan penilaian kinerja dan penilaian autentik merupakan penilaian kinerja dengan menggunakan tugas dunia nyata, autentik dan konteks.Disebut sebagai penilaian alternatif karena penilaian autentik sebagai alternatif untuk penilaian tradisional.Terakhir, disebut sebagai penilaian langsung karena penilaian autentik menyediakan lebih banyak bukti langsung dari aplikasi bermakna dari pengetahuan dan keterampilan.

Archbald (1991) menjelaskan bahwa penilaian autentik adalah setiap jenis penilaian yang menuntut siswa untuk menunjukkan keterampilan dan kompetensi yang realistis mewakili masalah dan situasi yang mungkin ditemui dalam kehidupan sehari-hari.Siswa diminta untuk menghasilkan ide-ide, untuk mengintegrasikan pengetahuan, dan untuk menyelesaikan tugas-tugas yang memiliki aplikasi dunia nyata.Pendekatan seperti ini membutuhkan orang yang mampu membuat dan menggunakan penilaian dalam penerapan penilaian berpatokan.

Penilaian autentik mementingkan penilaian proses dan hasil sekaligus. Dengan demikian, seluruh tampilan siswa dalam rangkaian kegiatan pembelajaran dapat dinilai secara objektif, apa adanya, dan tidak sematamata hanya berdasarkan hasil akhir (produk) saja. Lagi pula, amat banyak kinerja siswa yang ditampilkan selama berlangsungnya kegiatan pembelajaran sehingga penilaiannya harus dilaksanakan selama dan sejalan dengan berlangsungnya kegiatan proses pembelajaran. Jika dilihat dari sudut pandang teori Bloom-sebuah model yang dijadikan acuan pengembangan penilaian dalam beberapa kurikulum di Indonesia sebelum ini-penilaian haruslah mencakup ranah kognitif, afektif, dan psikomotorik (Nurgiyantoro, 2008, p.251). Seperti dimuat dalam www.park.educetlquicktipsauthassess. html mengontraskan antara penilaian autentik dan penilaian tradisional dalam tabel berikut. 
90 Jurnal Pendidikan Bahasa dan Sastra, Volume 17, Nomor 1, April 2017, blm. 81-97

Tabel 3. Perbedaan antara penilaian autentik dan penilaian tradisional

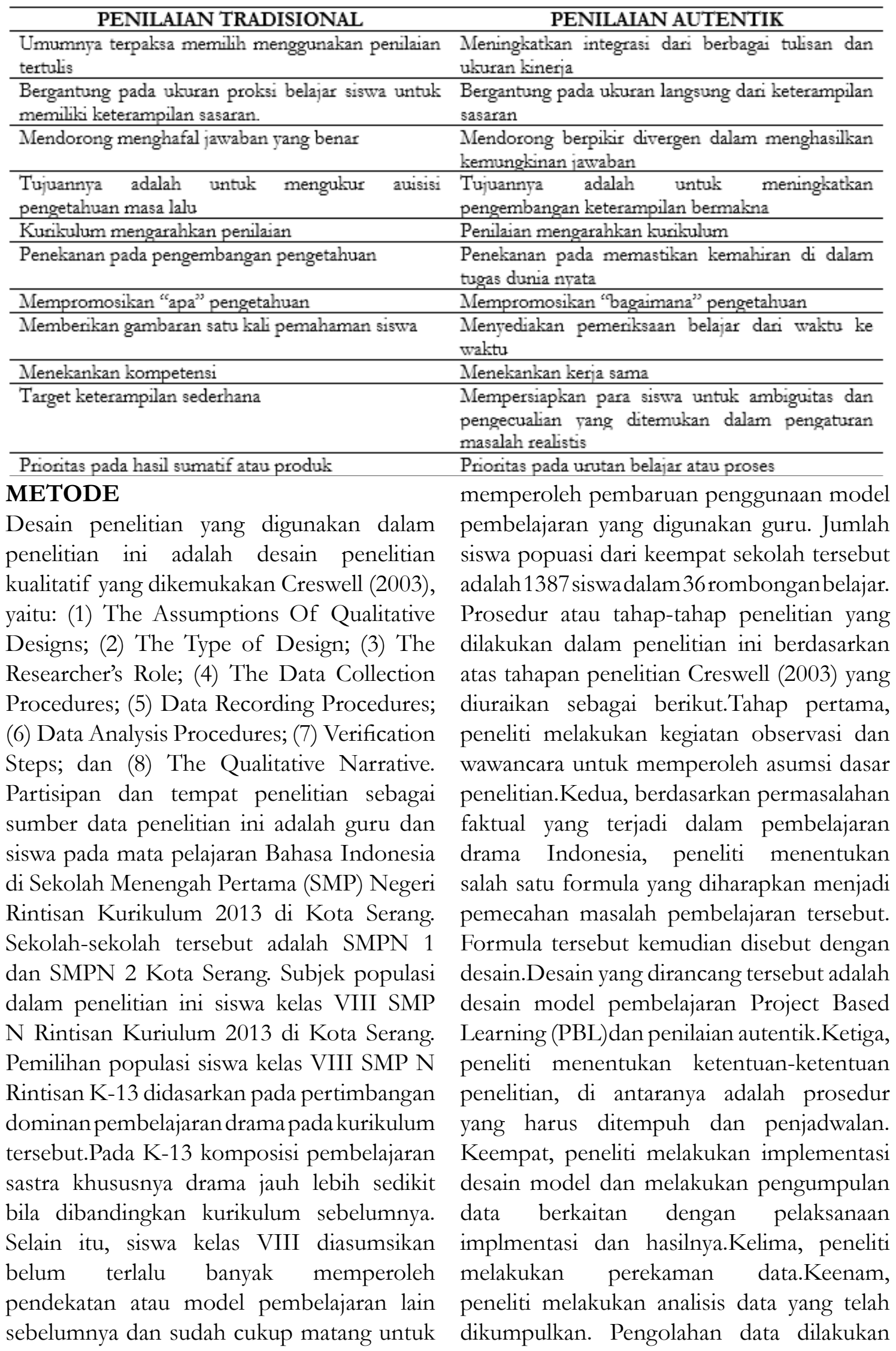


dengan melakukan pengelompokan dan pengkategorian berdasarkan permasalahan penelitian. Data dianalisis dengan keperluan bahwa implementasi model pembelajaran Project-based learning (PBL) dan penilaian autentik perlu dianalisis untuk dapat dideskripsikan secara jelas tahap demi tahap penerapan model ini. Data ini akan menjelaskan efektifitas proses implementasi model pembelajaran Project Based Learning (PBL) dan penilaian autentik serta hasil implementasi tersebut.Ketujuh, peneliti melakukan verifikasi langkah-langkah penelitian dan implementasi model untuk memastikan penelitian dan implementasi model telah dilaksanakan dengan benar; dan kedelapan, penelitian mendeskripsikan hasil penelitian.

\section{HASIL DAN PEMBAHASAN}

Implementasi Model Pembelajaran Project Base Learning (PBL) dan Penilaian Autentik dalam Pembelajaran Drama Indonesia

Secara praktis model pembelajaran project-based learning (PBL) dan penilaian autentik dalam pembelajaran drama Indonesia berbentuk sintaks atau langkah-langkah pembelajaran. Langkah-langkah pembelajaran tersebut diuraikan dalam tabel berikut.

Tabel 4. Langkah-langkah pembelajaran model pembelajaran project based learning (PBL) dan penilaian autentik dalam pembelajaran drama Indonesia

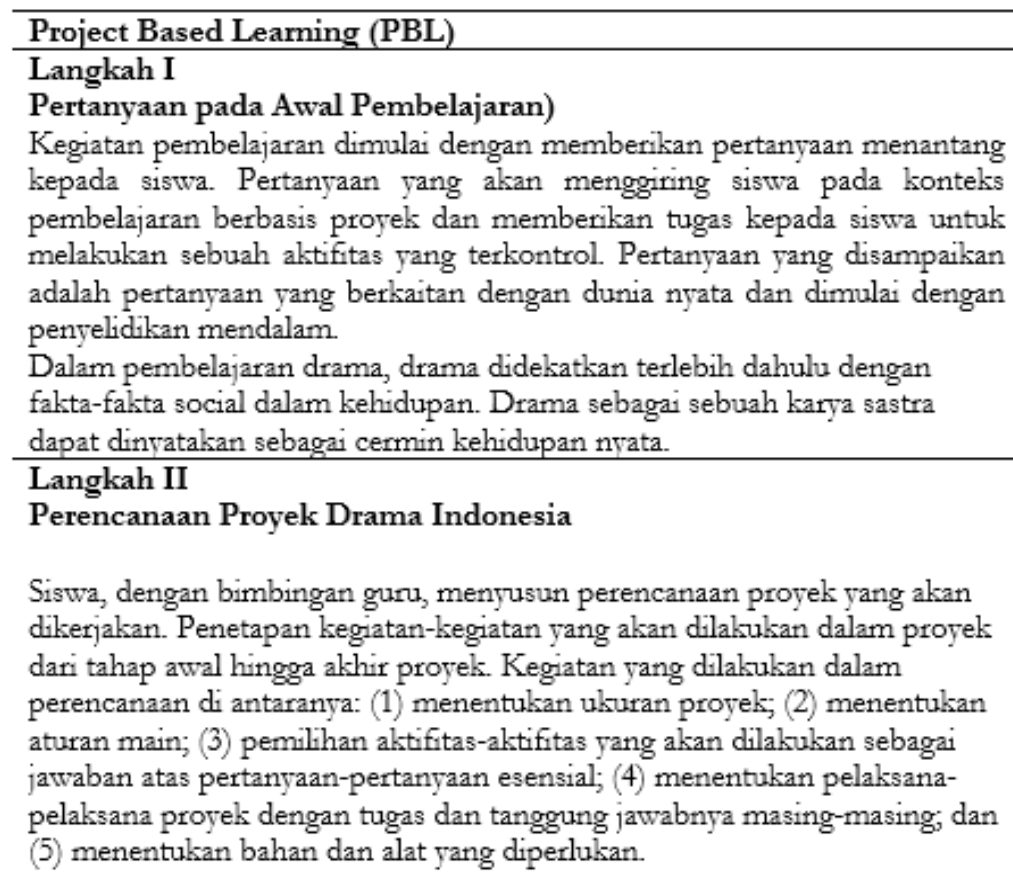

\section{Langkah III}

Penjadwalan Tahap Kegiatan Proyek

Siswa dengan bimbingan guru diminta membuat sebuah jadwal kegiatan yang akan dilakukan berdasarkan perencanaan aktivitas-aktivitas yang akan dilakukan. Tujuan kegiatan ini adalah memberikan pemahaman kepada siswa bahwa untuk melakukan sebuah proyek yang besar, sebuah kelompok kerja membutuhkan jadwal kerja yang baik agar proyek dapat dilaksanakan sesuai rencana. Meskipun demikian, kegiatan ini diupayakan dilakukan dengan sederhana dan tidak membingungkan siswa, mislnya dengan memberikan contoh jadwal kegiatan yang pernah ada.

Kegiatan yang dijadwalkan di antaranya:

a. latihan olah volsal;
Penilaian Autentik

Rubrik I

Rubrik Sikap (Motivasi Belajar

Drama Indonesia)

Rubrik II

Rubrik Bekerja dalam

Kelompok

Rubrik III

Rubrik Ketepatan Perencanaan

Pagelaran Drama Indonesia
Rubrik IV

Rubrik Ketepatan Penjadwalan

Kegiatan dan presentasi

rencana kegiatan Pagelaran

Drama 
92 Jurnal Pendidikan Bahasa dan Sastra, Volume 17, Nomor 1, April 2017, blm. 81-97

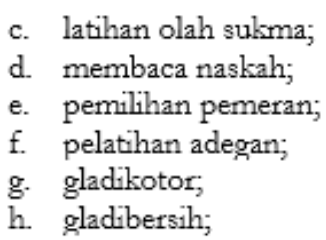

Setelah mendapatkan pengarahan dari guru, siswa dapat melakukan kegiatan ini di luar jam pembelajaran biasa. Hal ini dilakukan agar siswa tidak diburu waktu yang singkat dan dapat memunculkan kreativitas mereka. Siswa dapat melakukan eksplorasi dan memperoleh sumber inspirasi yang lebih luas. Siswa mempresentasikan hasil penyusunan jadwal mereka pada kegiatan pembelajaran di sekolah sebagai bentuk tanggung jawab. Kegiatan ini dapat berupa kegiatan pembelajaran tambahan atau kegiatan kokurikuler.

Pertemuan ke-2 s.d ke-4 (di luar jam belajar)

Langkah IV

Pengawasan Proyek Berjalan

Rubrik II

Siswa mendapat pengawasan dari guru. Pengawasan ini berfungsi bukan hanya sebagai sebuah kontrol kerja namun juga sebenamya merupakan sebuah proses pembimbingan. Monitoring dilakukan dengan memberikan fasilitas penuh kepada siswa untuk melakukan aktifitasnya dengan

\section{sempurna.}

\section{Pertemuan ke-5}

Langkah V

Penilaian

Rubrik V

Rubrik Pementasan/Pagelaran

Drama

Penilaian dilakukan terhadap hasil kerja siswa dalam proyeknya. Penilaian dilakukan untuk mengukur ketercapaian kompetensi siswa. Oleh karena itu, guru dituntut membuat penilaian seautentik mungkin.

\begin{tabular}{ll}
\hline Langkah VI & $\begin{array}{l}\text { Rubrik VI } \\
\text { Evaluasi Proyek }\end{array}$ \\
$\begin{array}{l}\text { Kegiatan pembelajaran diakhiri dengan kegiatan evaluasi proyek. Kegiatan (self } \\
\text { assessment) }\end{array}$ \\
$\begin{array}{l}\text { yang dilakukan adalah guru dan siswa melakukan refleksi pelaksanaan } \\
\text { proyek. Siswa diminta mengungkapkan apa saja yang telah mereka pahami } \\
\text { dan lakukan selama proyek berlangsung. Selain itu, siswa juga diminta } \\
\text { mengungkapkan perasaannya dan pengalaman baru vang mereka peroleh. }\end{array}$ \\
\hline
\end{tabular}

Kegiatan yang dilakukan guru dan siswa dengan menggunakan model pembelajaran tersebut diuraikan dalam tabel berikut.

Tabel 5. Kegiatan yang dilakukan guru dan siswa dengan menggunakan model PBL

\begin{tabular}{|c|c|c|}
\hline No. & Kegiatan Guru & Kegiatan Siswa \\
\hline 1. & $\begin{array}{l}\text { Pertemuan I } \\
\text { Guru membuka kegiatan pembelajaran dengan } \\
\text { mengucapkan salam, meminta salah saeorang siswa } \\
\text { memimpin berdoa, mengecek keadaan siswa, } \\
\text { menjelaskan kompetensi dasar, dan menjelaskan } \\
\text { kegiatan pembelajaran yang akan dilakukan. }\end{array}$ & $\begin{array}{l}\text { Siswa menjawab salam, berdoa, dan } \\
\text { memperhatikan penjelasan guru. }\end{array}$ \\
\hline 2. & $\begin{array}{l}\text { Guru memberikan petanyaan esensial tentang drama } \\
\text { untuk mendekatkan pemahaman drama siswa dengan } \\
\text { kehidupan sehari-hari. Guru melakukan penilaian } \\
\text { dengan mennggunakan rubrik sikap motivasi. }\end{array}$ & $\begin{array}{l}\text { Siswa melakukan } 11 \text { anya jawab berkaitan } \\
\text { dengan hubungan drama dengan } \\
\text { kehidupan sehari-hari dan pengalaman } \\
\text { mereka berkaitan dengan drama dengan } \\
\text { antusias. }\end{array}$ \\
\hline
\end{tabular}


3. Guru membagi siswa dalam beberapa kelompok Siswa bersama kelompok melakukan proyek, memberikan penjelasan tentang proyek kegiatan perencanaan proyek dengan pertunjukan drama, dan memberikan kepercayaan bimbingan guru sampai penyusunan jadwal kepada siswa untuk melaksanakan proyek mereka. kegiatan proyek. Guru memberikan contoh penjadwalan kegiatan dalam provek. Guru melakukan penilaian dengan menggunakan rubric kerja sama dalam kelompok, ketepatan perencanaan dan penjadwalan.

\begin{tabular}{|c|c|c|}
\hline 4. & $\begin{array}{l}\text { Pertemuan II s.d IV } \\
\text { Guru melakukan monitoring dan penilaian proyek } \\
\text { berjalan. }\end{array}$ & $\begin{array}{l}\text { Siswa bersama kelompok mereka bekerja } \\
\text { melaksanakan proyek sesuai dengan } \\
\text { perencanaan dan jadwal yang telah mereka } \\
\text { susun sebelumnya. Kegiatan tidak hanya } \\
\text { dilakukan di dalam ruang kelas. } \\
\text { Pembelajaran juga dilakukan di tempat } \\
\text { yang nyaman bagi mereka. Kegiatan ini } \\
\text { juga dilakukan pada waktu yang lain (di luar } \\
\text { jam belajar) bagi kelompok yang } \\
\text { menginginkannya. Antusias siswa } \\
\text { dibuktikan dengan keseriusan mereka } \\
\text { melaksanakan proyek sesuai dengan tugas } \\
\text { dan tanggung jawab masing-masing. }\end{array}$ \\
\hline 5. & $\begin{array}{l}\text { Pertemuan } V \\
\text { Guru melakukan pengkondisian pertunjukan drama } \\
\text { dan penilaian dengan menggunakan rubrik parameter } \\
\text { pertunjukan drama. }\end{array}$ & $\begin{array}{l}\text { Siswa melakukan pertunjukan drama } \\
\text { bersama kelompok mereka. Sementara satu } \\
\text { kelompok sedang menampilkan } \\
\text { pertunjukan siswa dan kelompok lain } \\
\text { menjadi penonton. Pertunjukan semakin } \\
\text { meriah dan memotivasi siswa karena } \\
\text { ditonton pula oleh kelas VIII yang lain. }\end{array}$ \\
\hline 6. & $\begin{array}{l}\text { Pertemuan VI } \\
\text { Guru melakukan pengkondisian pertunjukan drama } \\
\text { dan penilaian bagi kelompok yang belum tampil pada } \\
\text { pertemuan V karena waktu yang tidak mencukupi. } \\
\text { Guru juga melakukan kegiatan evaluasi bersama siswa } \\
\text { setelah pertunjukan selesai dengan membagikan rubric } \\
\text { penilaian diri. } \\
\text { Pada akhir pmbelajaran guru bersama siswa melakukan } \\
\text { kegiatan refleksi. }\end{array}$ & $\begin{array}{l}\text { Siswa bersama kelompok yang belum } \\
\text { tampil pada pertemuan V melakukan } \\
\text { pertunjukan drama. } \\
\text { Siswa melakukan penilaian diri (self } \\
\text { assessment) dengan mengisi rubric yang } \\
\text { dibagikan guru. } \\
\text { Siswa melakukan kegiatan refleksi dengan } \\
\text { bimbingan guru. }\end{array}$ \\
\hline
\end{tabular}

Hasil Implementasi Model Pembelajaran Serang. Untuk mengukur keberhasilan Project Based Learning (PBL) dan implementasi model, peneliti menggunakan Penilaian Autentik dalam Pembelajaran rubric penilaian pertunjukan drama sebagai Drama Indonesia

Implementasi model tersebut dilakukan pada parameter tanpa mengabaikan penilaiandua sekolah yaitu SMPN 1 dan SMPN 2 Kota penilaian dengan rubrik yang lain. Berikut nilai hasil implementasi model tersebut. 
94 Jurnal Pendidikan Bahasa dan Sastra, Volume 17, Nomor 1, April 2017, blm. 81-97

Tabel 6. Hasil implementasi model PBL

\begin{tabular}{|c|c|c|}
\hline $\begin{array}{l}\text { NOMOR } \\
\text { SAMPEL }\end{array}$ & $\begin{array}{c}\text { NILAI SMPN } 1 \\
\text { KOTA SERANG }\end{array}$ & $\begin{array}{l}\text { NILAI SMPN } 2 \\
\text { KOTA SERANG }\end{array}$ \\
\hline 1 & 3.56 & 3.38 \\
\hline 2 & 3.19 & 3.94 \\
\hline 3 & 3.81 & 3.31 \\
\hline 4 & 3.13 & 3.19 \\
\hline 5 & 3.38 & 4.00 \\
\hline 6 & 3.38 & 3.88 \\
\hline 7 & 3.56 & 3.38 \\
\hline 8 & 3.88 & 3.88 \\
\hline 9 & 3.63 & 3.81 \\
\hline 10 & 3.75 & 3.81 \\
\hline 11 & 3.38 & 3.63 \\
\hline 12 & 3.38 & 4.00 \\
\hline 13 & 3.06 & 3.38 \\
\hline 14 & 3.31 & 3.81 \\
\hline 15 & 3.19 & 3.56 \\
\hline 16 & 3.81 & 3.81 \\
\hline 17 & 3.50 & 3.50 \\
\hline 18 & 3.31 & 3.63 \\
\hline 19 & 3.56 & 3.06 \\
\hline 20 & 3.88 & 4.00 \\
\hline 21 & 4.00 & 3.75 \\
\hline 22 & 3.06 & 3.13 \\
\hline 23 & 3.19 & 3.75 \\
\hline 24 & 3.56 & 3.31 \\
\hline 25 & 3.69 & 4.00 \\
\hline 26 & 3.94 & 4.00 \\
\hline 27 & 3.75 & 3.38 \\
\hline 28 & 3.81 & 3.56 \\
\hline 29 & 3.63 & 3.63 \\
\hline 30 & 3.19 & 3.69 \\
\hline 31 & 3.63 & 3.56 \\
\hline 32 & & \\
\hline 33 & & \\
\hline 34 & & \\
\hline 35 & & \\
\hline 36 & & \\
\hline 37 & & \\
\hline 38 & & \\
\hline
\end{tabular}

Nilai Rata-Rata 
Uraian nilai per item kriteria penilaian yang menunjukan kompetensi atau kemampuan siswa dalam melaksanakan setiap bagian drama diuraikan sebagai berikut.

Tabel. Uraian nilai per item kriteria penilaian kompetensi siswa dalam setiap bagian drama

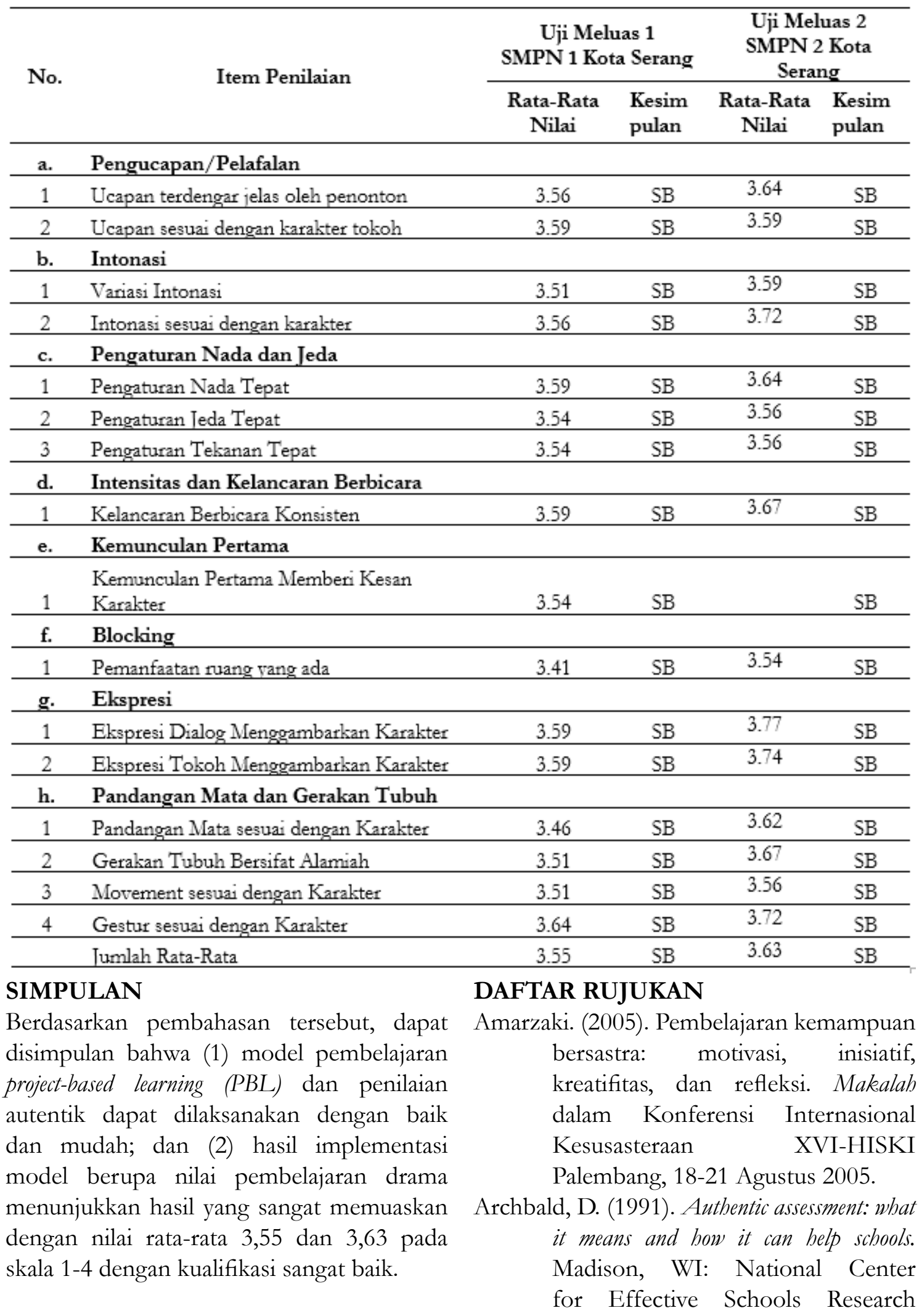


and Development, University of Wisconsin. Diakses tanggal 3 Maret 2013 dari http://www.ncrel.org/ sdrs/areas/issues/envrnmnt/stw/ sw1refer.htm.

Brears, L., MacIntyre, B. \& O’Sullivan, G.(2011). Preparing teachers for the 21st century using PBL as an integrating strategy in science and technology education. Design and Technology Education: An International Journal, 16(1), 36-46.

Capraro, M. M., Capraro, R. M., \& Morgan, J. R. (Eds.). (2013). STEM projectbased learning: An integrated science, technology, engineering, and mathematics. Dari http:// sensepublishers.com/ media/1522-stem-project-basedlearning.pdf

Cresswell,J.W.(2003). Research design qualitative, quantitative, and mixed methods Approaches. (2nd edition). California: SAGE Publication International Educational And Profesional Publisher.

Hamid, A. (2007). Teori belajar dan pembelajaran. Jakarta: Rineka Cipta.

Irawan, I.P.A.U., Sudiana, I.N., \& Wendra, I.W. (2014). Penggunaan film bisu dengan teknik dubbing untuk meningkatkan kemampuan menyampaikan dialog dalam drama siswa kelas XII IPA 1 di SMA Negeri 2 Negara. Jurnal Pendidikan Bahasa dan Sastra Indonesia. Vol. 2 No. 1 Tahun 2014. Diakses dari http://ejournal. undiksha.ac.id/index.php/JJPBS/ article/view/2526.

Jagantara, I M. W., Adnyana, P. B, \& Widiyanti, N. L. P. M. (2014). Pengaruh model pembelajaran berbasis proyek (Project Based Learning) terhadap hasil belajar biologi ditinjau dari gaya belajar siswa SMA. e-journal Program Pascasarjana Universitas Pendidikan Ganesha.Volume 4 (1).
Lindawati, F., Siska D., \& Maftukhin, A. (2013). Penerapan model pembelajaran project based learning untuk meningkatkan kreativitas siswa MAN I Kebumen. Jurnal Radiasi, Vol. 3, (1). Hlm. 42-45.

Marantika, J.E.R. (2014). Drama dalam pembelajaran bahasa dan sastra. Tahuri, Vol. 11 (2). Agustus 2014.

Miller, A. (2012). PBL and standardized tests? it can work! Diakses pada 25 April 2015. dari: http://www.edutopia. org/blog/PBL-and-standardizedtests-andrew-miller.

Nurgiyantoro, B. (2011). Penilaian autentike dalam pembelajaran bahasa. Yogyakarta: Gadjah Mada University Press.

Pryor, C. R., \& Kang, R.. (2013). Projectbased learning: an interdisciplinary approach for integrating social studies with STEM dalam R.M. Capraro, M.M. Capraro and J. Morgan (eds.), STEM Project-based learning: an integrated science, technology, engineering and mathematics (STEM) approach, 129-138. Rotterdam: Sense Publishers.

Rais, M. (2010). Project based learning: inovasi pembelajaran yang berorientasi soft skills. Makalah dalam Seminar Nasional Pendidikan Teknologi dan Kejuruan Fakultas Teknik Universitas Negeri Surabaya 11 Desember 2010.

Roessingh, H. \& Chambers, W. (2011). Project-based learning and pedagogy in teacher preparation: staking out the theoretical Mid-Ground. International Journal of Teaching and Learning in Higher Education, Volume 23 (1).

Samanthis, A. \& Sulistyo, E. (2014). Pengembangan perangkat pembelajaran menggunakan model Project based learning pada Standar Kompetensi memperbaiki Radio Penerima di SMKN 3 Surabaya. 
Jurnal Pendidikan Teknik Elektro, Volume 03, (01), Tahun 2014.

Setiaji, A.N., (2014). Pengembangan model kooperatif modeling the way dengan teknik Rendra dalam pembelajaran bermain drama bermuatan pendidikan karakter pada Peserta Didik SMP Kelas VIII. Seloka: Jurnal Pendidikan Bahasa dan Sastra Indonesia. Diakses dari: http://journal.unnes. ac.id/sju/index.php/seloka/article/ view/ 6625

Suryatin, H.E. (1997). Efektivitas model mengajar resepsi dan pendekatan resepsi sastra dalam pengajaran sastra untuk meningkatkan kemampuan apresiasi sastra (Rangkuman Disertasi). Bandung: PPS-IKIP.

Sutrisna, GRA., Nengah, M., Arifin. (2013). Evaluasi dalam pembelajaran drama di kkelas XI IA1, SMA Negeri SeKota Singaraja. Jurnal Penelitian Pascasarjana Undiksha. Diakses dari: http://pasca.undiksha.ac.id/ejournal/index.php/jurnal_bahasa/ article/view/533
Syukron, A., Subyantoro, \& Yuniawan, T. (2016). Peningkatan keterampilan menulis naskah drama dengan metode picture and picture. Jurnal Pendidikan Bahasa dan Sastra Indonesia. Diakses dari: http:// journal.unnes.ac.id/sju/index.php/ jpbsi.

The George Lucas Educational Foundation (2003). Diakses pada 23 April 2015, dari: https://prezi.com/ky_fz_eah7rd/ steps-for-project-based-learning/.

Wajdi, F. (2017). Pengembangan model pembelajaran Project based learning (PBL) berbantuan penilaian autentik dalam pembelajaran drama Indonesia. Bandung: Disertasi belum diterbitkan.

Weyers, M. (2012). PBL Pilot: 4 strategies to implement and spread PBL in your school. Diakses pada 25 April 2015 dari: http://www. Edutopia.org/blog/ pbl-pilot-implement-spread-yourschool-matt-weyers-jen-dole.

Vega, V. (2012). Project-based learning research review. Diakses pada tanggal 25 April 2015, dari: http://edutopia.org/pblresearch-learning-outcomes. 